\title{
A Flash Charge System for Urban Transport
}

\author{
Adriano Alessandrini \\ D.I.C.E.A. \\ University of Florence \\ Florence, Italy \\ adriano.alessandrini@unifi.it \\ Edoardo Locorotondo \\ D.I.E.F. \\ University of Florence \\ Florence, Italy \\ edoardo.locorotondo@unifi.it \\ Antonino Genovese \\ E.N.E.A. \\ Casaccia-Rome, Italy \\ antonino.genovese@enea.it
}

\author{
Fabio Cignini \\ D.I.C.E.A. \\ University of Florence \\ Florence, Italy \\ fabio.cignini@unifi.it \\ Marco Pierini \\ D.I.EF. \\ University of Florence \\ Florence, Italy \\ marco.pierini@unifi.it \\ Fernando Ortenzi \\ E.N.E.A. \\ Casaccia-Rome, Italy \\ fernando.ortenzi@enea.it
}

\author{
Riccardo.Barbieri \\ D.I.E.F. \\ University of Florence \\ Florence, Italy \\ riccardo.barbieri@unifi.it \\ Luca Pugi \\ D.I.E.F. \\ University of Florence \\ Florence, Italy \\ luca.pugi@unifi.it
}

\begin{abstract}
-flash charge systems represent a potentially interesting application for urban transport systems especially if relatively low distances between intermediate stops are recorded. Also this technology assures the complete removal of catenaries or other kind of continuous power collection systems whose usage should be limited in historical or archeological sites. In this work authors describe design, assembly and some preliminary activities concerning a fully working prototype able to demonstrate feasibility and main features of the proposed system
\end{abstract}

Keywords - fast charge, hybrid storage systems, prototyping of real time systems, green sustainable urban transportation

\section{INTRODUCTION}

Proposed system is briefly described in figure 1 .

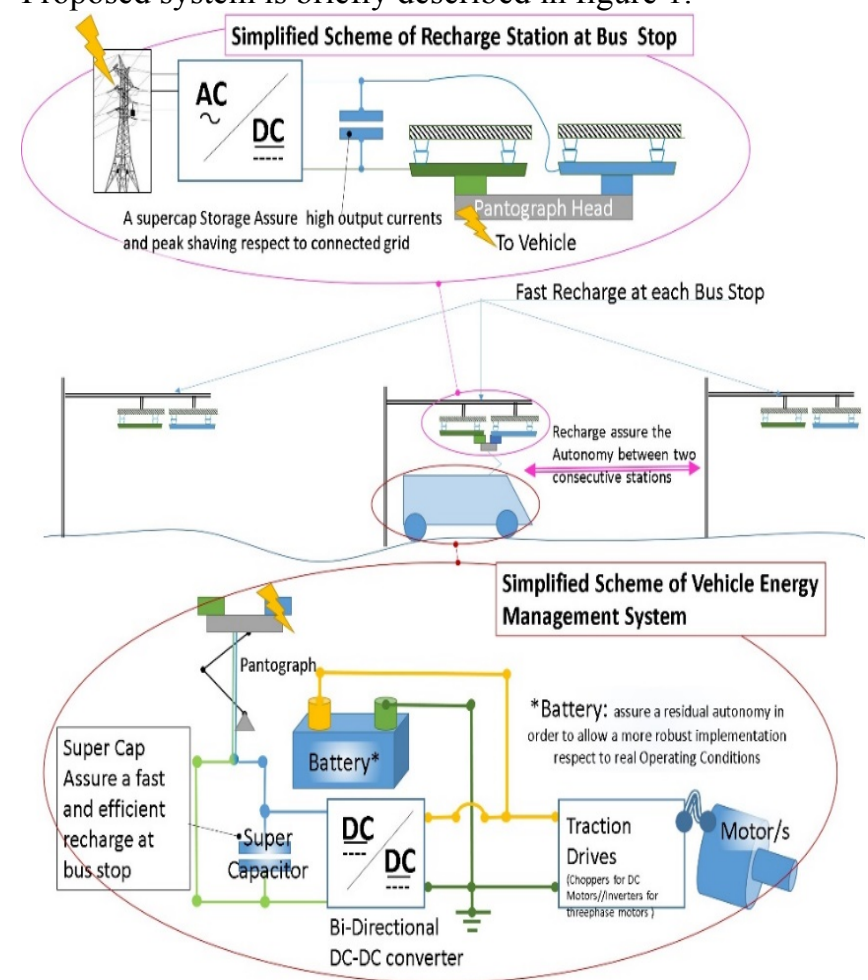

Fig. 1. Simplified Scheme of the Proposed System

At each bus stop a system of super-capacitors is used to produce the high currents need to implement an appreciable power transfer in the relatively small pause allowed during a bus stop (about 30s). Traction system is coupled to the storage one using a bi-directional DC-DC converter in order to compensate large voltage fluctuations of super-capacitors. In order to assure a further backup autonomy of the vehicle, an additional storage system with higher energy density is provided. The resulting hybrid storage system assures a good compromise in terms of fast recharge and efficiency offered by super-capacitors with a cautious additional autonomy assured by conventional batteries. In this way, it's also possible to assure an overall robustness and resilience of the system respect to design and service uncertainties that should affect energy consumptions between two bus stops. Proposed solution is aligned with recent works available in literature such as the ones of Tarsitano[1] or Barrade[2]. However, respect to literature the proposed work offers three aspects of innovation and originality:

1)First, the real implementation on a full scale test case;

2) A limited use of power converters;

3) A simple and resilient control architecture easily customizable to different vehicle configurations.

To demonstrate this desirable features of the proposed solutions authors tries to apply this technology to an existing electric bus (TECNOBUS Gulliver ESP 520) without modifying in any way its pre-existing traction and powertrain systems.

\section{PROPOSED BENCHMARK}

Authors chose to apply the proposed flash charge system to revamp an existing electric bus, the TECNOBUS Gulliver ESP 520 who has been widely experimented for public transportation in Florence[3] and in many other towns in Italy. Also this vehicle was available and instrumented at ENEA-Casaccia Laboratories so it was relatively simple to perform further experimental runs in order to verify vehicle behavior in different running conditions. Main geometrical features of the vehicle are described in figure 2, while some data concerning the vehicle and some main components of its power management system are shown in Table I.

Finally dimensions of the vehicle were not too big making easier the logistic management of the revamping works; also authors[4] have some experience of similar, small size, electric buses. This electric vehicle has its own existing 
traction plant, so aim of the activity is a simple revamping of his storage and power management system.

TABLE I: COMPARATIVE ENERGY CONSUMPTIONS

\begin{tabular}{ll}
\hline Vehicle Parameters $*$ & Value \\
\hline Weight (Tare/Maximum) & $4270 / 6045[\mathrm{~kg}]$ \\
Batteries (kind/capacity/weight) & Lead Acid/ 595[Ah] @ 72[V]/1500[kg] \\
Inst.Traction System (nom. peak power) & $21[\mathrm{~kW}] / 25[\mathrm{~kW}]$ \\
Lights and on board instr. (power) & $200[\mathrm{~W}]$ \\
Air Conditioning System ** & $2[\mathrm{~kW}]$ \\
$*$ Parameters are referred to the original Gulliver bus before authors retrofit \\
**The bus used for the first demonstrator was not equipped with an air conditioning \\
unit, however authors have preliminary established a feasible size of the system \\
\hline
\end{tabular}

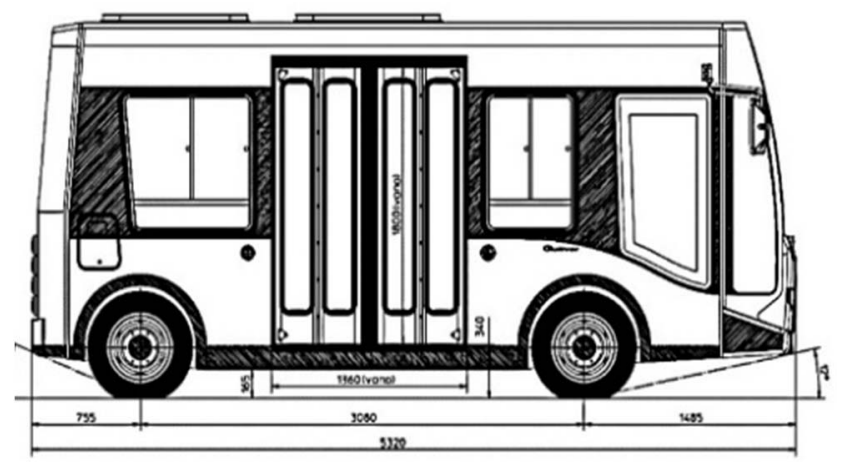

Fig. 2. Simplified Scheme of the Proposed System

\section{SizING SPECIFICATIONS ACCORDING EXPECTED MISSION PROFILE}

In order to properly size storage and power management systems, some preliminary considerations on vehicle mission profiles has to be performed. First a mean ideal trajectory between two adjacent bus-stops, described in figure 3, (recorded data on a real maneuver), it's considered. With a travelled distance of about $750 \mathrm{~m}$ (almost plain, no slope) and a max speed of about $35 \mathrm{~km} / \mathrm{h}$ (nominal loading conditions), the resulting consumed energy, shown in figure 3 , it's relatively small and approximately equal to $100 \mathrm{Wh}$.

Also considering power (energy derivatives) during the traction phase mean consumed power seems to be not much variable respect to a mean value of $10-15 \mathrm{~kW}(12 \mathrm{~kW})$.

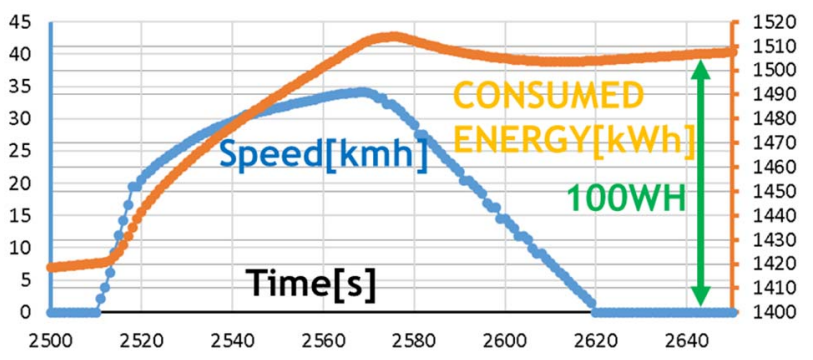

Fig. 3. Energy consumption corresponding to the maneuver of figure 3

These preliminary calculations were further refined by considering the statistical study of recorded service data (corresponding to several months of equivalent service of a single bus). These data showed quite larger deviations in terms of energy consumptions which can be largely justified by the variability of real operating conditions and mission profiles as visible in the examples of figure 4: mean speed on real mission profiles are even lower than the supposed, but corresponding energy consumptions should be far higher than expected. The reasons for this behavior are several ones: traffic and loading conditions, road orography, suboptimal driving styles etc. As a consequence, a more cautious energy consumption between bus stops of about 300Wh was considered.

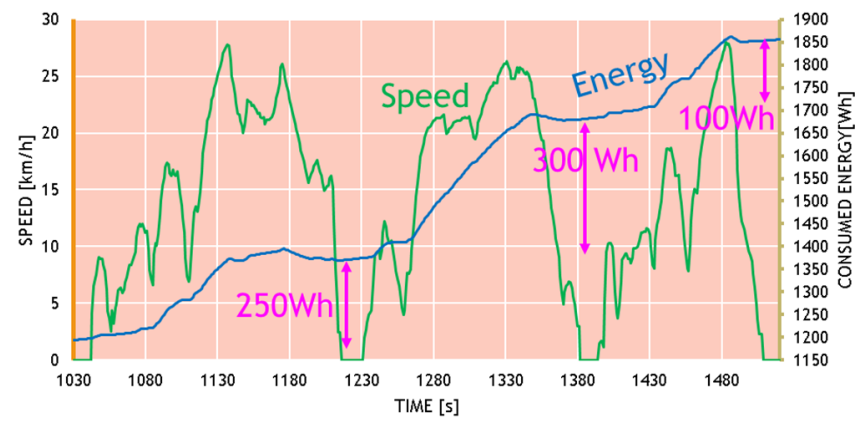

Fig. 4. Example of variability in terms of energy consumptions and speed profiles between three consecutive bus stops

Also some statistical indexes have been evaluated: in figure 5 mean kilometric consumptions respect to different speed are shown. It's interesting to notice that higher consumptions are associated to lower speed where harder and more frequent energy consuming maneuvers are statistically more commons.

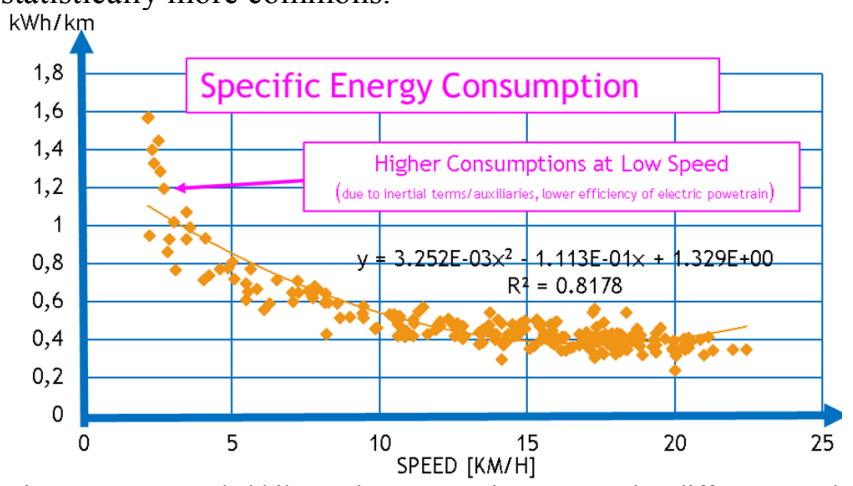

Fig. 5. Mean recorded kilometric consumption measured at different speed

\section{PRELIMINARY SIZING OF VEHICLE SUPERCAPACITORS}

Assuming a needed storage of about $300 \mathrm{Wh}$, and assuming the usage of commercial components, authors decided to employ three series connected modules whose main features are described in Table II. The maximum energy $E_{t h}$ that can be stored by chosen modules with capacity $C$ can be calculated according (1) leading to a value of stored energy (420Wh). This value is calculated considering the nominal max voltage $V$ of the module $(125 \mathrm{~V})$, and it is far higher than the one required by specifications $(300 \mathrm{Wh})$.

$$
E_{t h}=\frac{1}{2} C V^{2} \approx 420 W h
$$

However, it should be also considered that a feasible management of the energy stored in super capacitors involves a limitation of the minimum operating voltage $V_{\min }$ which is typically about an half respect to the nominal one. Taking count of this minimal operational constraints, the energy stored on capacitors module $\left(E_{\text {real }}\right)$ can be recalculated according (2) leading to a more cautious evaluation which is still aligned with system specifications:

$$
E_{\text {real }}=\frac{1}{2} C\left(V^{2}-V_{\text {min }}^{2}\right) \approx 300-350 W h
$$


Capacitors are connected in series in order to reduce the value of charge currents that have to be collected during the recharge phase: in particular considering a current collection phase of 30 seconds and a constant power input, the involved power request is about $36 \mathrm{~kW}$ leading to more than reasonable current values $(\max 20-25$ [A]). However, for this specific applications also the system chosen for a fast recharge of super-capacitors have deeply influenced the design of the systems. In particular recharge of super capacitors was supposed to be performed using a passive substations also composed by an array of six super-capacitor modules (different solutions are possible) equals to the ones adopted for the vehicle that have been previously described in Table II.

\section{TABLE II: MAIN FEATURES OF SUPER CAPACITOR MODULES}

\begin{tabular}{ll}
\hline Component Parameter & Value \\
\hline Installed Super Capacitors & three Maxwell BMOD0063 P125 \\
& series connected \\
Weight (one module) & About $60[\mathrm{~kg}]$ \\
Capacity (one module) and Resistance & $63[\mathrm{~F}](63-76[\mathrm{~F}])-18[\mathrm{~m} \bullet]$ \\
Test Current for Capacitance and ESRDC & $100[\mathrm{~A}]$ \\
Rated//Maximum Voltage (one module) & $125[\mathrm{~V}] / / 136[\mathrm{~V}]$ \\
Max Series Voltage & $1500[\mathrm{~V}]$ \\
Maximum Current (Peak Value) & $1900[\mathrm{~A}]$ \\
\hline
\end{tabular}

With a direct connection between charged and discharged capacitors, inrush currents are relatively high (thousands of amperes). So the designers of the passive recharge station (which was managed by the research team of Prof. Lidozzi of Roma 3 University) adopted a configuration visible in figure 6[5]. An inductor is used in order to smooth current derivatives (power stored on peak currents is smoothly recovered during the final part of the recharge).

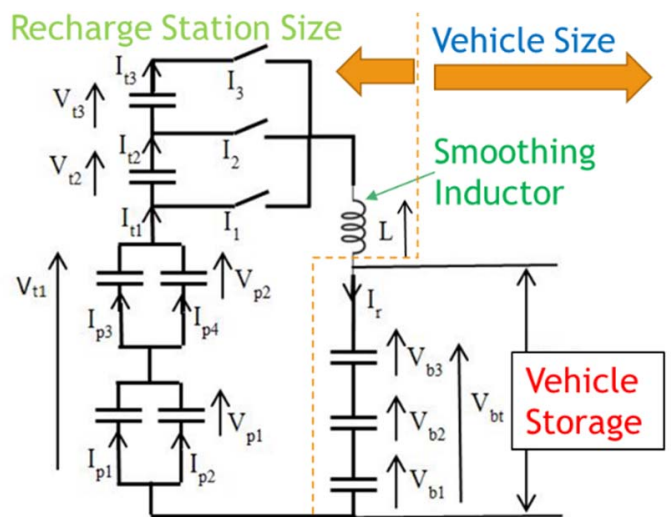

Fig. 6. Simplified Functional Scheme Of the Recharge Station Coupled with on board Storage system

Three contactors are alternatively opened and closed in order to produce three current impulses whose shape is briefly described in figure 7 where the process has been deliberately extended to 60 seconds in order to make clear that most of the power is transmitted in three current pulses whose real duration is not more than 6-7 seconds. Obviously in this case currents are relatively high so the chosen series configuration of vehicle super capacitors is quite justified.

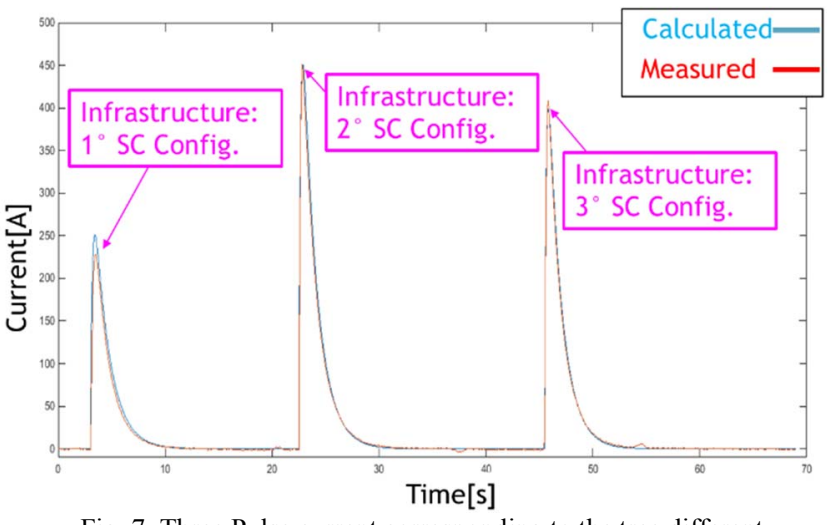

Fig. 7. Three Pulse current corresponding to the tree different configurations of the fixed station during the recharge process

\section{PRELIMINARY SizING OF VEHICLE DC-DC CONVERTERS}

As visible in the scheme of figure 1, energy stored on vehicle super capacitors has to be transferred to traction motors using a DC-DC converter. For the investigated vehicle, DC level of traction motors is the same of the batteries that have originally equipped the vehicle and it's equal to about $72 \mathrm{~V}$.

Also for these components authors focused their choice on commercial products: in this case it was chosen a modular system by TAME-Tronico ${ }^{\mathrm{TM}}$ which assures the desired power performance using an array of converter modules that can be easily mounted in paralleled multiple units in order to achieve desired performances. Some technical details concerning the chosen converter module are described in Table III.

TABLE III: MAIN FEATURES OF DC-DC CONVERTERS

\begin{tabular}{ll}
\hline Component Parameter & \multicolumn{1}{c}{ Value } \\
\hline DC-DC Converter & COMET Series by TAMETM \\
Weight (one module) & About $11[\mathrm{~kg}]$ \\
Power (min/mean/max) & $5 / 6.5 / 8[\mathrm{~kW}]$ depending on voltage level \\
Efficiency & About $92 \%$ (mean nom. power) \\
Control Mode & Current Controlled (buck/boost) \\
\hline
\end{tabular}

In order to properly size authors considered two reference mission profiles which are represented in figure 8:

- A maximum performance recorded during some tests performed on the roller rig of ENEA CASACCIA laboratories: the vehicle is accelerated and suddenly braked in order to exploit maximum available performances of the traction system.

- Some records of real mission profiles experimentally measured during on the real vehicle during a mission.

Performances of the chosen DC-DC converters in terms of managed power are variable respect to voltages on capacitors since the real limitation is represented by maximum currents which for the same transferred power are clearly dependent from voltage levels. Also considering this parametric performance variability, the power transfer assured by two parallel connected modules is absolutely superior to what is needed to manage currents due to regenerative braking.

For the traction phase, two modules are able to cover the demand of the system in most common cases except peak requests associated to maximum performances. However, the usage of a third module in parallel is still not advisable and not only for a mere question of cost or encumbrances 
(which are not negligible) but also for efficiency reasons. Efficiency of largely oversized DC-DC converters (three modules) should be quite poor at partial loads where a less cautious design (two modules) has to be preferred. Finally it should be noticed that small additional loads should be still managed using backup batteries that are still installed on the vehicle in order to assure a residual autonomy in case of failure or unavailability of the fast recharge system.

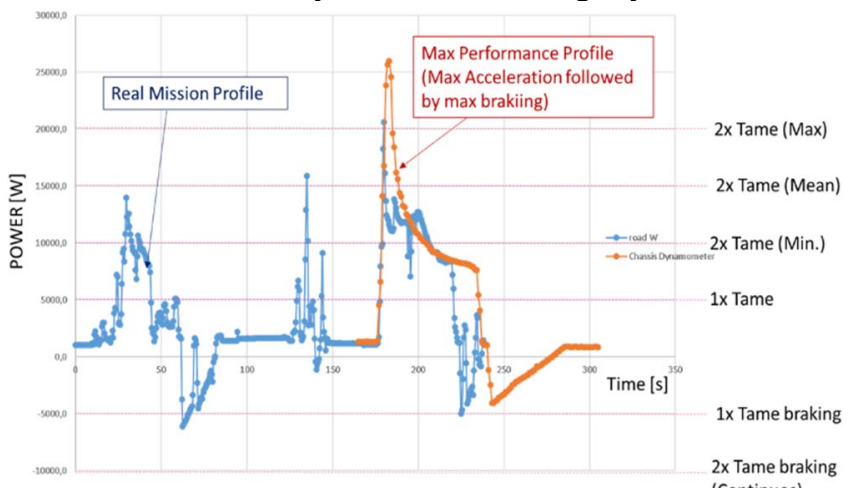

Fig. 8. Three Pulse current corresponding to the tree different configurations of the fixed station during the recharge process

\section{PRELIMINARY SIZING OF VEHICLE BACK-UP BATTERIES}

All the over described power electronics (Super-Capacitors and DC-DC converters) have been installed in the same sliding frame that was originally designed as recover for the original lead batteries of the vehicle. In this preliminary phase of development, authors use the remaining available space to place backup batteries. In order to avoid additional cost and modifications of the plant in this first implementation a lower quantity of lead batteries is reused in order to exploit existing space inside the vehicle without affecting in anyway volumes that should be used for the commercial transportation of passengers. As visible in figure 9, capacitors, power electronics and backup batteries occupies a space that was originally completely filled by lead batteries. Resulting performances of this reduced backup battery pack are described in table IV.

The chosen battery system is able to assure a residual autonomy of the vehicle for at least $8-10 \mathrm{~km}$ and can manage a significant power interacting with super capacitors and power converters.

It's noticeable that the new batteries assure a vehicle weight reduction of at least $3-400 \mathrm{Kg}$ respect the original configuration of the vehicle even considering weight and encumbrances due to all the other performed modifications.

For this reason, it should probably have re-evaluated also the increase of efficiency of vehicle due to a mere weight reduction respect to the original one. Finally, it should be considered in a further short end scenario the substitution of current lead batteries with cheap and robust lithium ones: even using cheap $\mathrm{LiFePO}_{4}$ modules, with the same size the power capacity should be at least doubled and further weight reductions are highly advisable.
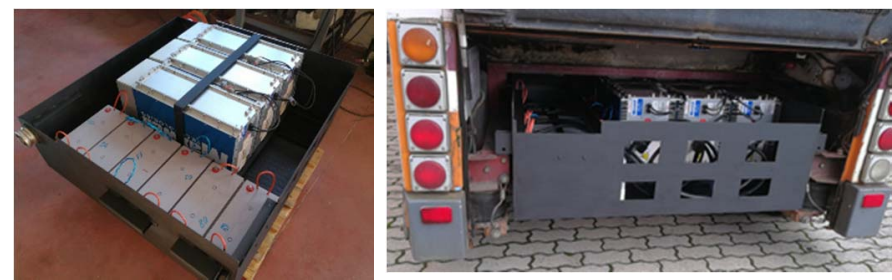

Fig. 9. Three Pulse current corresponding to the tree different configurations of the fixed station during the recharge process

TABLE IV: MAIN FEATURES OF BACK-UP BATTERIES

\begin{tabular}{ll}
\hline Component Parameter & \multicolumn{1}{c}{ Value } \\
\hline Battery Module & Fiamm 12FGL120 \\
Weight (one module) & About $38[\mathrm{~kg}]$ \\
Power Size (one module) & $120 \mathrm{Ah}$ \\
Layout & 7 modules $/$ batteries Series Connected \\
Total Stored energy (weight) & About $8600-8700 \mathrm{kWh}(270[\mathrm{~kg}])$ \\
\hline
\end{tabular}

\section{INTEGRATION OF CURRENT COLLECTION SYSTEM}

In order to properly recharge the bus at each bus-stop a Schunk SLS 101 pantograph has been installed on the vehicle of the roof of the vehicle as visible in figure 10 .

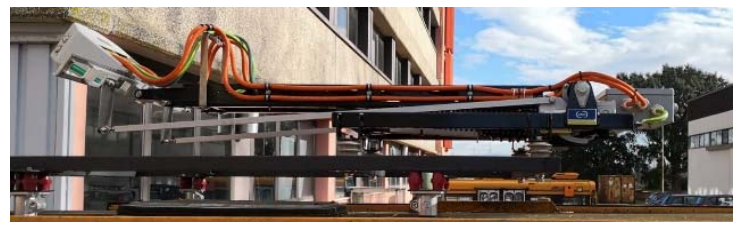

Fig. 10. Schunk SLS 101 Pantograph installed on the roof of the bus prototype

The equivalent mass of pantograph and its actuation system is about $100 \mathrm{~kg}$, and the vehicle roof, a very light fiberglass structure, has to be modified in order to make possible this installation. Considering also the small size of the benchmark test vehicle this operation was not originally so easy to be performed.

Authors developed a quite original solution that is briefly described in figure 11: original roll bars that are usually applied in the bus to assure the stability of passengers, were removed and substituted with a structural tubular structure. This structure maintains the original function of roll bars but it is also able to assure the stability of the pantograph reinforcing the whole vehicle body with negligible weight increments or losses in terms of internal volumes available for passengers.

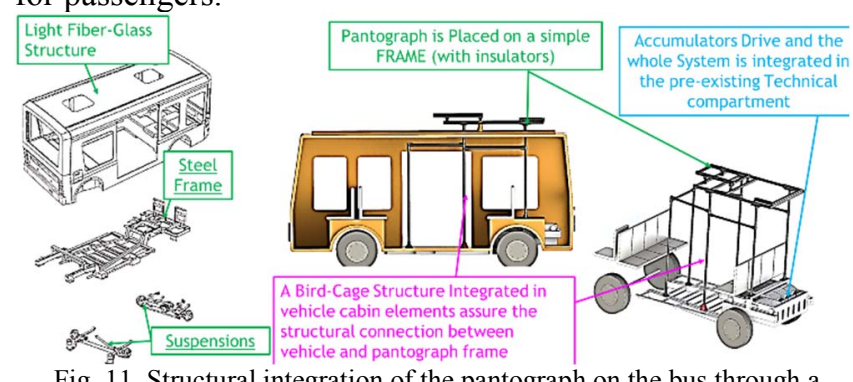

Fig. 11. Structural integration of the pantograph on the bus through a tubular, "bird cage" structure designed by the authors

\section{SIMPLIFIED CURRENT BATTERY LOOP CONTROL SYSTEM}

There is a wide literature concerning the optimal control of hybrid storage systems[6] [7] but their immediate applicability on the proposed system should be probably 
evaluated in future due to fact that this kind of approaches originally developed for generic hybrid storage systems have to be highly customized for the specific application.

An interesting work is represented by the contribution of Tarsitano [1]: where a fuzzy logic system is adopted to manage the correct blending within on board batteries and the super capacitors used for flash charge. In the work of Tarsitano the fuzzy controller tries to implement the following criteria:

- Try to follow vehicle energy demand maintaining batteries in an optimal state of charge reducing multiple energy conversion that should negatively affect efficiency and thermal behavior;

- Maximize the usage of the energy of super capacitors;

- Slightly reduce the use of super-capacitors only when they are near to be empty;

In the proposed systems, similar results are obtained adopting a simple current control scheme with a limited number of non linear or scheduled blocks that can be easily calibrated as visible in the scheme of figure 12: first, according the current state of charge of the battery, it's calculated a value of current $\left(I_{r e f}\right)$ that should be applied by the DC-DC converters, to the battery to provide a corresponding smooth efficient recharge using the energy stored in super-capacitors. The system is regulated using a current closed loop whose actuators/active elements are the DC-DC converters connected to super capacitors. DC-DC converters are configured as current servo-amplifiers; they provide the desired output current taking the power from connected super capacitors.

Since it's a closed loop scheme, there is no need to measure additional loads due to other vehicle systems since they are treated as disturbances which have to be naturally rejected by the loop. The proposed regulator is a simple proportional one. A scheduling of the proportional gain respect to battery or capacitors state of energy/charge can be easily used to better calibrate the system.

To better understand the behaviour of the proposed control system the following simplifications/assumptions have to be supposed valid:

- System can be approximated and solved as an LTI one (Linear Time Invariant);

- Energy conversion losses and other nonlinear phenomena are neglected;

- Bandwidth of external disturbances is very low respect to the one of the control system (supposed stable) so they can have treated as static contributions

Assuming as valid the over cited simplifications, the power required by vehicle loads $W_{L}$ can be treated as an equivalent static disturbance and all the system can be investigated using standard properties and rules used for LTI systems. In this way it's possible to calculate approximately how, in steady state conditions, the load $W_{L}$ should be distributed between capacitors and batteries (3)

$$
\begin{aligned}
& \overbrace{W_{\text {cap }}}^{\substack{\text { power } \\
\text { from } \\
\text { Capacitors }}} \approx W_{L} \frac{K_{p}}{1+K_{p}}+I_{\text {ref }} V_{\text {batt }} \frac{K_{p}}{1+K_{p}} ; \\
& \overbrace{W_{\text {batt }}^{\text {power }}}^{\substack{\text { Batteries } \\
\text { Brom }}} \approx W_{L} \frac{1}{1+K_{p}}-I_{\text {ref }} V_{\text {batt }} \frac{K_{p}}{1+K_{p}} ;
\end{aligned}
$$

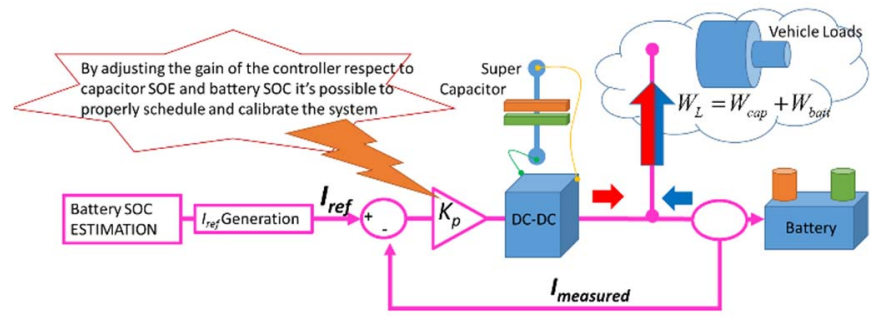

Fig. 12. Structural integration of the pantograph on the bus through a tubular, "bird cage" structure designed by the authors

In particular, by regulating the loop gain $K_{p}$ it is possible to choose between an aggressive load following strategy (high values of the gain) or a smoother one in which super capacitors provide a near to constant current to keep charged the battery like a classic range extender.

Approximated results of (3) have been also verified numerically using the simplified Simscape PowerSystem ${ }^{\mathrm{TM}}$ model represented in figure 13.

In figure 14 some results concerning a simulation with null reference current $\left(I_{r e f}=0\right)$ and a good gain $\left(K_{p}=5\right)$ are shown: a load current profile taken from previous experimental measurement is imposed to the system and the loop is able to regulate the current generated by the DC-DC converter in order to compensate a large part of this disturbance using the energy taken from super capacitors. The remaining current (the "error" of the closed loop) is exerted by the battery. Looking at results of figure 14, if we exclude some fast transient behaviors, it can be easily demonstrated that relation (3) is a good approximation of system behavior in steady state conditions.

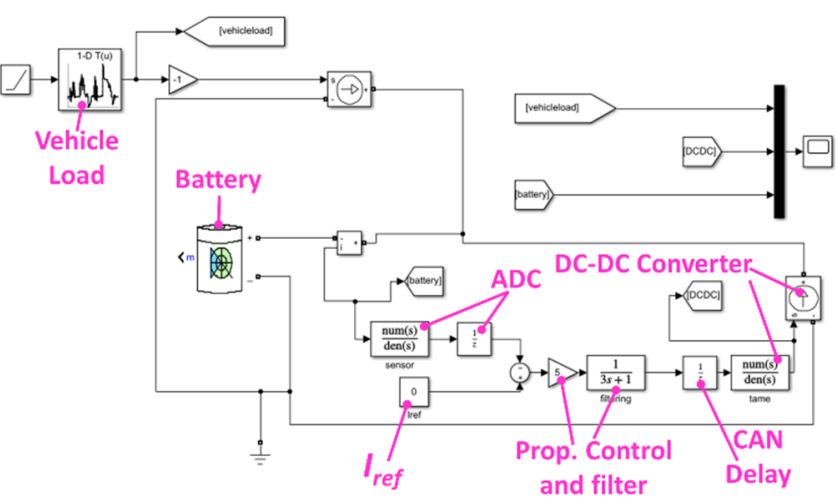

Fig. 13. Simplified model of the proposed control system 


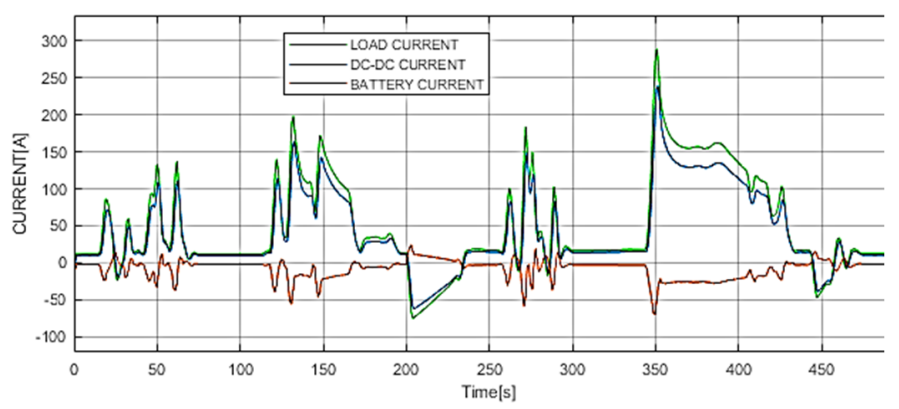

Fig. 14. Example of simulated behavior of the proposed control system

\section{CONCLUSIONS AND FUTURE DEVELOPMENTS}

In this work an innovative flash charge system to be applied on electric buses has been designed. Currently the system have been successfully assembled on an existing electric vehicle visible in figure 15 (external painting has to be redone but most of vehicle systems are ready to start).

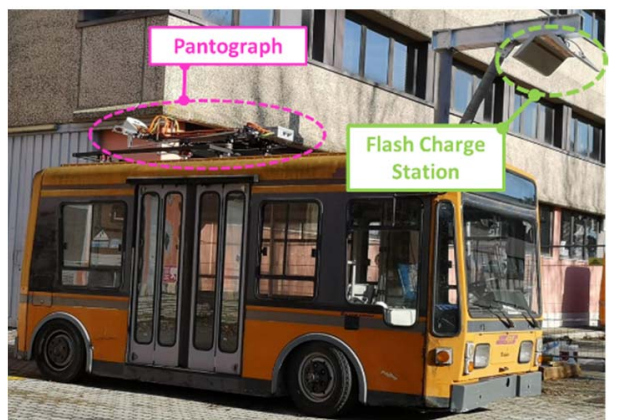

Fig. 15. The assembled system at ENEA CASACCIA Research Center

Experimental activities on the assembled demonstrator are going on and authors are quite confident to be able to obtain a wide variety of experimental results that should be the object of future publications. In the meanwhile the proposed system can be also proposed to other urban service vehicles such as the ones dedicated to garbage and waste collection on which authors have worked in past research activities[8]. Further possible applications compatible with a scaled application of the proposed solutions are substantially represented by tramways[9]. However further comparison should be performed considering hybrid solutions [10][11], different powertrains[12], or also the adoption of different wireless recharge technologies[13][14].

\section{ACKNOWLEDGMENT}

This activity has also involved the help of many people (researchers, technician etc.) that have provided their supports for the activities described in this work. Authors wish to thank all of them, recognizing that complex activities cannot be really managed with the help of a lot of different competences and skills that are too often under evaluated.

\section{REFERENCES}

[1] Yu, H., Tarsitano, D., Hu, X., Cheli, F. Real time energy management strategy for a fast charging electric urban bus powered by hybrid energy storage system (2016) Energy, 112, pp. 322-331. DOI: 10.1016/j.energy.2016.06.084

[2] P. Barrade and A. Rufer. Supercapacitors as energy buffers: a solution for elevators and for electric busses supply. In Proceedings of the Power Conversion Conference-Osaka 2002 (Cat. No.02TH8579), volume 3, ages 1160-1165. IEEE, 2002

[3] Barbieri, R., Giampreti, G., Berzi, L., Pierini, M., Event Simulation for an Electric Public Transportation System Using Real World Data: A feasibility and energetic analysis for the Firenze case study (2018) Proceedings - 2018 IEEE International Conference on Environment and Electrical Engineering and 2018 IEEE Industrial and Commercial Power Systems Europe, EEEIC/I and CPS Europe 2018, art. no. 8494498, DOI: 10.1109/EEEIC.2018.8494498

[4] Pugi, L., Grasso, F., Pratesi, M., Cipriani, M., Bartolomei, A.Design and preliminary performance evaluation of a four wheeled vehicle with degraded adhesion conditions (2017) International Journal of Electric and Hybrid Vehicles, 9 (1), pp. 1-32. DOI: 10.1504/IJEHV.2017.082812

[5] F. Ortenzi, M. Pasquali, G. Pede, A. Lidozzi, M. Di Benedetto, " Ultra-fast charging infrastructure for vehicle on-board ultracapacitors in urban public transportation applications", EVTeC and APE Japan on Sept.30-Oct.3, 2018.

[6] Yu, H., Cao, D. Multi-objective Optimal Sizing and Real-time Control of Hybrid Energy Storage Systems for Electric Vehicles (2018) IEEE Intelligent Vehicles Symposium, Proceedings, 2018June, art. no. 8500629, pp. 191-196. DOI: 10.1109/IVS.2018.8500629

[7] Wang, B., Xu, J., Wai, R.-J., Cao, B. Adaptive Sliding-Mode with Hysteresis Control Strategy for Simple Multimode Hybrid Energy Storage System in Electric Vehicles (2017) IEEE Transactions on Industrial Electronics, 64 (2), art. no. 7593317 , pp. 1404-1414. DOI: 10.1109/TIE.2016.2618778

[8] Pugi, L., Pagliai, M., Nocentini, A., Lutzemberger, G., Pretto, A. Design of a hydraulic servo-actuation fed by a regenerative braking system (2017) Applied Energy, 187, pp. 96-115. DOI: 10.1016/j.apenergy.2016.11.047

[9] Pugi, L., Grasso, F., Rossi, G. Energy Simulation of Tramway Systems, Simplified and Efficient Models (2018) Proceedings - 2018 IEEE International Conference on Environment and Electrical Engineering and 2018 IEEE Industrial and Commercial Power Systems Europe, EEEIC/I and CPS Europe 2018, art. no. 8494431, DOI: 10.1109/EEEIC.2018.8494431

[10] M. Ceraolo, S. Barsali, G. Lutzemberger, M. Marracci: "Comparison of SC and high-power batteries for use in hybrid vehicles", SAE Technical Paper 2009-24-0069, 2009.

[11] T. Huria, G. Lutzemberger, G. Pede, G. Sanna: "Systematic development of series-hybrid bus through modelling", Vehicle Power and Propulsion Conference (VPPC), 2010 IEEE, 1-3 Sept. 2010, Lille.

[12] Pugi, L., Grasso, F., Pratesi, M., Cipriani, M., Bartolomei, A. Design and preliminary performance evaluation of a four wheeled vehicle with degraded adhesion conditions(2017) International Journal of Electric and Hybrid Vehicles, 9 (1), pp. 1-32. DOI: 10.1504/IJEHV.2017.082812

[13] Pugi, L., Reatti, A., Corti, F. Application of Wireless Power Transfer to Railway Parking Functionality: Preliminary Design Considerations with Series-Series and LCC Topologies (2018) Journal of Advanced Transportation, 2018, art. no. 8103140, DOI: 10.1155/2018/8103140

[14] Pugi, L., Reatti, A., Corti, F. Application of modal analysis methods to the design of wireless power transfer systems, (2019) Meccanica, 54 (1-2), pp. 321-331. DOI: 10.1007/s11012-018-00940-x 